\title{
The influence of family's participation in recreational sports on its resilience and communication facilitation
}

\author{
Min-soo Cho* \\ Department of Exercise Rehabilitation \& Welfare, College of Health Science, Gachon University, Incheon, Korea
}

This study aims to define the influence of the motive and degree of family's participation in recreational sports on its resilience and communication facilitation. Of members of sports centers in Seoul and Gyeonggi areas, 202 people who participated in recreational sports together with their family members were sampled as the population. Input data were computerized for analysis, using PASW 22.0 and AMOS 18.0 programs. Data statistical processing methods of reliability analysis and structural equation modeling were used, and the results are outlined as follows. Motive for family's participation in recreational sports did not influence family resilience and communication facilitation. However, the degree of family's participation in recreational sports influenced family resilience and communication facilitation. Degree of family's participation in recreational sports did not directly influence communication facilitation, but boosted family resilience, further facilitating family communication. In other words, family resilience is an important parameter between recreational sports and communication facilitation.

Keywords: Recreational sports, Resilience, Communication facilitation

\section{INTRODUCTION}

Family is the most primary and essential group in the process of humans' socialization. Family is the smallest interaction social unit between people, and in this process, family members get emotional and psychological stability, thus becoming socially required healthy members. In this role, family is the most important space. However, rapid industrialization is drastically changing such family structure from a large-family unit to a core-family unit, thereby weakening the venue for socialization learning through social interaction (Yang, 2006).

Notably, such family structure change is raising questions about a healthy family, and presents the concept of family resilience and family communication as answers to such questions. First, family resilience refers to the ability to overcome possible crises and stress between family members and to repair their relationships (Hawley and Dehaan, 1996). Specifically, it is the characteristic designed to successfully overcome a big crisis situation between family members and adjust to the situation (Walsh, 2002). It was reported that an excellently resilient family has excellent communication ability between its members, and resolves problems altruistically (Walsh, 2002). Thus, the more resilient a family is, the better its members' communication ability is, indicating a positive correlation between the two variables.

As such, family resilience and communication facilitation is being diversely researched in social sciences, but research has yet to be furthered about how family resilience and family communication can be facilitated, using characteristics of family participation in recreational sports. However, it is reported that family participation in recreational sports facilitates communication between its members, and plays a positive role in the ability to minimize and cope with family conflicts or opinion difference (Jeong, 2006). Above all things, it is reported that recreational sports play a positive role in satisfaction and emotions between family members (Choi, 2003; Kim, 1999; Yi and Kang, 2009), so family's recreational sports are expected to significantly boost family resilience and communication facilitation.

Therefore, this study aims to define how the motive and degree
${ }^{*}$ Corresponding author: Min-soo Cho

Department of Exercise Rehabilitation \& Welfare, College of Health Science, Gachon University, 191 Hambakmoero, Yeonsu-gu, Incheon 461-701, Korea Tel: +82-32-820-4442, Fax: +82-32-820-4442, E-mail: ab9040@gachon.ac.kr Received: October 16, 2014 / Accepted: October 18, 2014
This is an Open Access article distributed under the terms of the Creative Commons Attribution Non-Commercial License (http://creativecommons.org/licenses/by-nc/3.0/) which permits unrestricted non-commercial use, distribution, and reproduction in any medium, provided the original work is properly cited. 
of family's participation in recreational sports facilitate family resilience and communication. To that end, this study established the following hypotheses. First, the greater the motive for family's participation in recreational sports is, the greater the family resilience is. Second, the greater the motive for family's participation in recreational sports is, the further the family communication is facilitated. Third, the greater the degree of family's participation in recreational sports is, the greater the family resilience is. Fourth, the greater the degree of family's participation in recreational sports is, the further the family communication is facilitated. Fifth, the greater the family resilience is according to the motive and degree of family's participation in recreational sports, the further the family communication is facilitated.

\section{MATERIALS AND METHODS}

\section{Research model}

This study established a research model, as Figure 1, involving family's participation in recreational sports, family resilience and family communication as variables, based on theoretical assumption and previous research results.

As in Figure 1, the motive and degree of participation were assumed as exogenous variables that directly or indirectly influence family resilience and communication facilitation. Family resilience was assumed as an endogenous variable that influences family communication facilitation.

Table 1 features exogenous and endogenous variables in the measurement structure for a structure model for the motive and degree of family's participation in recreational sports, family resilience and communication facilitation.

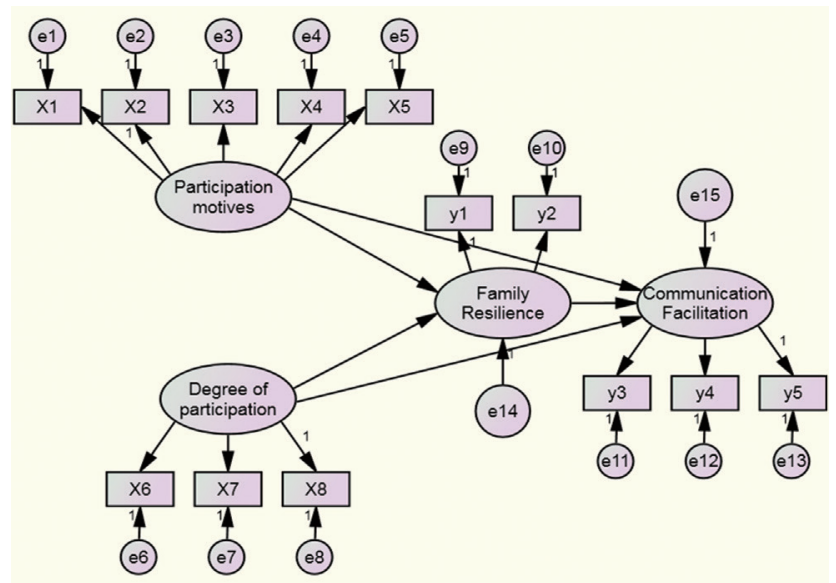

Fig. 1. Research model.

\section{Subjects}

To define the relations between family's participation in recreational sports, family resilience, and communication facilitation, families participating in recreational sports were sampled as the population, from those in Seoul and Gyeonggi areas, using the stratified cluster random sampling method. 240 subjects were sampled from sports centers in the region. 216 finally participated in the survey, but an effective 202 were analyzed. General characteristics of subjects are shown as in Table 2.

\section{Research tools}

A questionnaire was used to define the relations between family's participation in recreational sports, family resilience and communication facilitation.

The questionnaire consists of 4 socio-demographic questions, 5 participation motive questions, 3 participation degree questions, 18 family resilience questions, and 16 communication facilitation questions.

Table 1. Description of model

\begin{tabular}{|c|c|c|}
\hline Category & Theoretical variables & Measurement variables \\
\hline Exogenous variables & Motive for participation & $\begin{array}{l}\text { X1: Skill } \\
\text { X2: Joy } \\
\text { X3: Socialization } \\
\text { X4: Physical strength } \\
\text { X5: Showoff }\end{array}$ \\
\hline Exogenous variables & Degree of participation & $\begin{array}{l}\text { X6: Participation period } \\
\text { X7: Participation frequency } \\
\text { X8: Participation strength }\end{array}$ \\
\hline Endogenous variables & Family resilience & $\begin{array}{l}\text { Y1: Philosophy } \\
\text { Y2: Organization pattern }\end{array}$ \\
\hline Endogenous variables & Communication facilitation & $\begin{array}{l}\text { Y3: Acceptance } \\
\text { Y4: Burden } \\
\text { Y5: Satisfaction }\end{array}$ \\
\hline
\end{tabular}

Table 2. General characteristics of subjects

\begin{tabular}{llcc}
\hline Category & & No. of people & Frequency (\%) \\
\hline Total & & 202 & 100.0 \\
Gender & Males & 109 & 54.0 \\
& Females & 93 & 46.0 \\
Age & 40s or under & 23 & 11.4 \\
& 40s & 74 & 36.6 \\
& 50s & 79 & 39.1 \\
& 60s or above & 26 & 12.9 \\
Education & High school & 42 & 20.8 \\
& University & 124 & 61.4 \\
& Graduate school or higher & 36 & 17.8 \\
Income & KRW 2.5 mn or under & 17 & 8.4 \\
& KRW 2.5 mn-5 mn & 143 & 70.8 \\
& KRW 5 mn or above & 42 & 20.8 \\
\hline
\end{tabular}


First, socio-demographic questions consist of gender, age, education and income. Participation motive questions involved measurement variables, e.g., skill, joy, socialization, physical strength and showoff, and were complemented based on questions which were based on Vallerand and Bissonnett's SMS-28 (sport motivation scale) (1992). Each item was measured on the scale of 'Not at all (1 point)', 'Not so (2 points)', 'fairly so (3 points)', 'so (4 points)', and 'Very much so (5 points)'. Also, participation degree questions consist of period, frequency, and strength as measurement variables.

Furthermore, the measurement tool for the parameter of family resilience was based on the revision of the family resilience measure, which was used by Hyun (2007). Questions consist of two sub-variables of philosophy and organizational pattern based on the 5-stage Likert scale. Each question was measured based on the scale of 'Not so at all (1 point)', 'Not so (2 points)', 'Fairly so (3 points)', 'So (4 points)', and 'Very much so (5 points)'.

In addition, the measurement tool for the dependent variable of family communication facilitation was based on the modification and implementation of the communication facilitation measurement tool which was developed by Williams and Giles (1996) and standardized by Lim (1999). The measure of family communication facilitation consists of 3 sub-variables of acceptance, burden and sat-

Table 3. Reliability of exogenous and endogenous variables

\begin{tabular}{lccc}
\hline Composition concept/measurement scale & No. of questions & Reliability \\
\hline Exogenous & [Participation motive] & {$[5]$} & 0.712 \\
variables & X1: Skill & 1 & \\
& X2: Joy & 1 & \\
& X3: Socialization & 1 & \\
& X4: Physical strength & 1 & \\
& X5: Showoff & 1 & \\
& [Participation degree] & {$[3]$} & 0.742 \\
& X6: Period & 1 & \\
& X7: Frequency & 1 & \\
& X8: Strength & 1 & \\
Endogenous & [Family resilience] & {$[18]$} & 0.817 \\
variables & Y1: Philosophy & 9 & \\
& Y2: Organizational pattern & 9 & \\
& [Communication facilitation] & {$[16]$} & 0.851 \\
& Y3: Acceptance & 7 & \\
& Y4: Burden & 6 & \\
& Y5: Satisfaction & 3 & \\
\hline
\end{tabular}

isfaction based on the 5-stage Likert scale. Each question was measured on the scale of 'Not so at all, (1 point)', 'No so (2 points)', 'fairly so (3 points)', 'so (4 points)', and 'Very much so (5 points)'.

\section{Questionnaire and its validity and reliability}

Validity refers to the reference by which it is judged whether or not the content or phenomenon that a researcher intends to observe is accurately observed or identified. To examine the reliability of the questionnaire, the reliability of variables was verified. Details are shown in Table 3 .

\section{Research procedure and data processing}

The survey was conducted by investigators who, after being trained in the survey, visited the interviewees in related areas. Input data were computerized using SPSS WIN 16.0 and AMOS 16.0 programs. Statistical data processing methods of reliability analysis and structural equation modeling were used.

\section{RESULTS}

\section{Verification of suitability of research model 1) Model verification}

This study seeks to verify the suitability of the relation between the motive and degree of family's participation in recreational sports, family resilience and family communication facilitation, and then to verify the hypotheses included in the research model. In this study, the structural model was verified using $\chi^{2}, \chi^{2} / \mathrm{df}$, GFI, AGFI, RMSEA, NFI, and CFI. Table 4 shows the result of verifying the suitability of the model.

As shown in Table 4, the research model had a very large $\chi^{2}$ value (494.660), and did not meet other suitability index criteria, presumably because covariance between estimated error terms were created and because statistically insignificant paths existed. Thus, in explaining the relation between family's participation in recreational sports, family resilience and family communication facilitation, it is deemed meaningless to discuss the relation between the suitability of the practically unsuitable model and variables.

Therefore, in this case, the model should be developed by revising, complementing and suggesting it (Anderson and Gerbing, 1988).

Table 4. Overall indices for verifying the suitability of the structural model

\begin{tabular}{lccccccc}
\hline Overall indices & $\chi^{2}(\mathrm{df}) / p$ & $\chi^{2} / \mathrm{df}$ & GFI & AGFI & RMSEA & NFI & CFI \\
\hline Structural model & $494.660(60) / 0.0$ & 8.244 & 0.852 & 0.824 & 0.190 & 0.792 & 0.817 \\
Suitability criteria & $P>0.05$ & $\leq 5$ & $\geq 0.90$ & $\geq 0.90$ & $\leq 0.08$ & $\geq 0.90$ & $\geq 0.90$ \\
Result of assessment & Unsuitable & Unsuitable & Unsuitable & Unsuitable & Unsuitable & Unsuitable & Unsuitable \\
\hline
\end{tabular}


Table 5. Revised model assessment

\begin{tabular}{|c|c|c|c|c|c|c|c|c|}
\hline Model & Revision & $\chi^{2}(d f) / p$ & $\chi^{2} / \mathrm{df}$ & GFI & AGFI & RMSEA & NFI & $\mathrm{CFI}$ \\
\hline Revised model & $\begin{array}{l}\text { Insignificant paths were removed; } \\
\text { covariance between error terms } \\
\text { was removed }\end{array}$ & $228.236(28) / 0.0$ & 2.362 & 0.923 & 0.936 & 0.041 & 0.977 & 0.968 \\
\hline $\begin{array}{l}\text { Research model vs. } \\
\text { revised model }\end{array}$ & $\begin{array}{l}\chi^{2}=494.660-228.236=266.424 \\
D f=60-28=32\end{array}$ & $\nabla(\nabla) / \times$ & $\nabla$ & $\triangle$ & $\triangle$ & $\nabla$ & $\triangle$ & $\triangle$ \\
\hline Result of assessment & & Unsuitable & Suitable & Suitable & Suitable & Suitable & Suitable & Suitable \\
\hline
\end{tabular}

Table 6. Verification of hypotheses

\begin{tabular}{clccc}
\hline Hypothesis & \multicolumn{1}{c}{ Hypothesis path } & $\begin{array}{c}\text { Path } \\
\text { coefficient }\end{array}$ & $\begin{array}{c}\text { Significance } \\
\text { level }\end{array}$ & $\begin{array}{c}\text { Adopt or } \\
\text { dismiss } \\
\text { hypothesis }\end{array}$ \\
\hline Hypothesis 1 & $\begin{array}{l}\text { Motive for participation } \\
\rightarrow \text { family resilience }\end{array}$ & 0.003 & 0.635 & Dismissed \\
Hypothesis 2 & $\begin{array}{l}\text { Motive for participation } \\
\rightarrow \text { communication facili- } \\
\text { tation }\end{array}$ & 0.321 & 0.403 & Dismissed \\
Hypothesis 3 & $\begin{array}{l}\text { Degree of participation } \\
\rightarrow \text { family resilience }\end{array}$ & 0.766 & 0.000 & Adopted \\
Hypothesis $4 \begin{array}{l}\text { Degree of participation } \\
\rightarrow \text { communication facili- } \\
\text { tation }\end{array}$ & 0.426 & 0.031 & Adopted \\
Hypothesis 5 & $\begin{array}{l}\text { Family resilience } \\
\rightarrow \text { communication } \\
\text { facilitation }\end{array}$ & 0.624 & 0.000 & Adopted \\
\hline
\end{tabular}

\section{2) Revised model and model comparison}

Using the revised model, the path by which the motive for family's participation in recreational sports influences family resilience and family communication facilitation was removed before showing the suitability of the revised model.

According to Table 5, $\chi^{2}$ value was found to be statistically significant; thus, the hypothesis can be dismissed. However, what is important here is that even if $\chi^{2}$ value is large and its probability is very small, thus making a significant difference, the proposed model with the suitability well reflecting the reality is highly likely to be a good model.

In addition, other conditions for model verification could not be met, so such assessment that depends entirely on $\chi^{2}$ value would be very dangerous, and the final conclusion should be based on considering other various adequate indices. $\chi^{2} / \mathrm{df}$ results from dividing $\chi^{2}$ by degree of freedom, and also is referred to as standard chisquare, which addresses the shortcomings of $\chi^{2}$ value, thus adequately evaluating the unsuitability of the model. If this value is $3-5$, it is considered a generous suitability level. Chi-square statistics have the limits of being sensitive to the effect of sample size, thus making the standard chi-square value likewise susceptible.

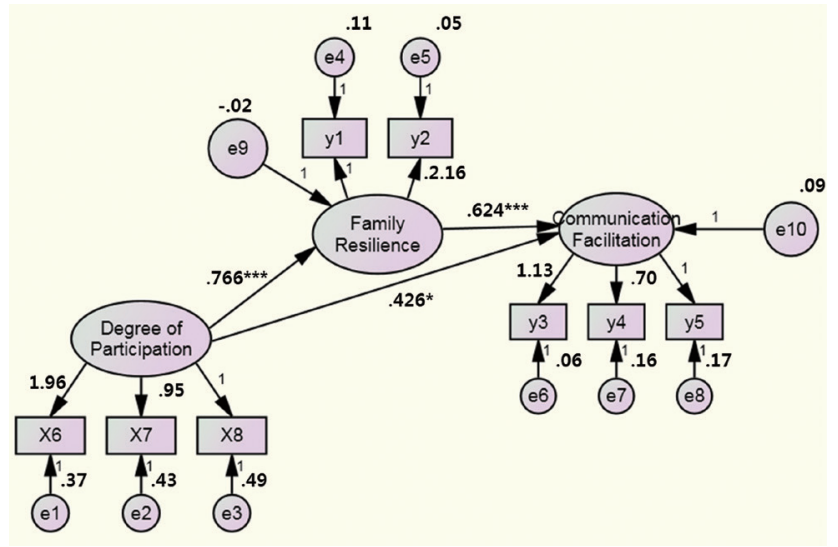

Fig. 2. Revised model.

However, with $\chi^{2} / \mathrm{df}$ being 2.362 , the proposed structural model is generally suitable to the given data. The revised model's other suitability indices also meet suitability criteria, suggesting an overall improvement.

Therefore, the findings of this research revealed that the degree of family's participation in recreational sports, rather than the motive thereof, was an important variable that influenced family resilience and family communication facilitation.

\section{Verification of hypotheses}

Table 6 shows the result of revising and verifying the relation between the degree of family's participation in recreational sports, family resilience and family communication facilitation.

According to Table 6, the degree of participation influences family resilience, which in turn influences family communication facilitation. However, it was revealed that the motive for participation did not directly influence family resilience and family communication facilitation.

Therefore, hypotheses 1 and 2 were dismissed, and hypotheses 3, 4, and 5 were adopted (Table 6).

Figure 2 shows the revised model based on Table 6 . According to Figure 2, the degree of family's participation in recreational sports directly influenced family communication facilitation 
(0.426), but more greatly facilitated family communication only through the family resilience parameter $(0.766 * 0.624=0.478)$.

Therefore, family resilience is an important parameter between the degree of family's participation in recreational sports and family communication facilitation. Specifically, to further facilitate family communication, family resilience should be heightened.

\section{DISCUSSION}

This study aims to define how a family can overcome its members' problems or difficulty according to the motive and degree of its participation in recreational sports. It is also studied how such overcoming capacity influences communication facilitation between family members in a bid to provide the basic data for the relation between family's participation in recreational sports, family resilience and family communication. Thus, this chapter discusses family's participation in recreational sports, family resilience and family communication facilitation based on related research results.

First, the motive for family's participation in recreational sports did not influence family resilience (hypothesis 1 dismissed). According to Koo and Lee (2013), the greater the motive for elderly people's participation in recreational sports is, the greater the recovery resilience is, suggesting that the motive for participation is an important variable for resilience, which contradicts the proposed hypothesis 1 . Such difference may come from a difference in the hypothesis verification process or subjects. This needs to be re-verified later.

Second, the motive for family's participation in recreational sports did not influence family communication facilitation (hypothesis 2 dismissed). Like hypothesis 1 , the motive for participation under hypothesis 2 did not have important effects on communication facilitation. Thus, in the process of establishing the proposed research model, it is considered that the motive for family's participation in recreational sports does not have important effects on family resilience or communication facilitation variable.

Third, the degree of family's participation in recreational sports influenced family resilience (hypothesis 3 adopted). Specifically, if a family positively participates in recreational sports, they can easily overcome their difficulty and crisis through unity. This result, as reported by Yi and Kang (2009), suggests that family's positive participation in recreational sports can have positive effects on family resilience's philosophy and organizational pattern. Notably, it was found that family's participation in physical leisure activities such as sports can help overcome crisis or difficulty through cooperation between its members, which supports the results of this study. Thus, physical leisure activities can bring positive effects to family resilience, which needs to be further proved through more studies.

Fourth, the enhanced degree of family's participation in recreational sports has a more positive effect on family communication facilitation (hypothesis 4 adopted). Specifically, those who positively participated in recreational sports together with their family members had a high acceptance level of communication. Notably, it was found that a positive participation in physical leisure activities such as sports plays a positive role in facilitating family communication, thus emphasizing the importance of family's participation in leisure activities.

In this regard, Jeong (2006) reports that family's participation in recreational sports creates positive results in relation to family communication, which supports this study. Also, the findings of this study show that family's physical leisure activities had positive effects on family communication. This suggests that positive recreational sports are an important variable for communication facilitation between parents and children. Thus, a lack of communication between parents and children has emerged as an important social problem in Korean society, to which family's positive participation in recreational sports is deemed to be an important solution.

Fifth, according to the degree of family's participation in recreational sports, family resilience in the relation to family communication had positive effects on family communication (hypothesis 5 adopted). Specifically, if a family increasingly participates in recreational sports, they can try to more positively recognizing and overcoming difficulty or crisis or to overcome such difficulties through family cooperation; in this process, family communication is facilitated.

Communication is a key factor to the process of a family overcoming and coping with its problems. Specifically, mutual frank expression of feelings and clear communication between family members to solve their problems are key factors. Clear communication is a key to delivering clear and consistent messages, and helps clearly define crisis situations. Such effective and efficient family communication can be facilitated through recreational sports, and such physical leisure activities help a family in crisis have a positive mindset, and furthermore solve problems interdependently and cooperatively. Notably, in this process, more efficient and clear communication can be facilitated. Thus, aforementioned previous studies support the findings of this study, and suggest that physical activities are a more important factor for a family to function more resiliently and facilitate their communication. 
Conclusions are drawn from this study as follows: First, the motive for a family's participation in recreational sports does not influence family resilience. Second, the motive for a family's participation in recreational sports does not influence communication facilitation. Third, the greater the degree of a family's participation in recreational sports is, the greater family resilience is. Fourth, the greater the degree of a family's participation in recreational sports, the more family communication is facilitated. Fifth, the greater family resilience is, the more family communication is facilitated.

All this put together, the motive for a family's participation in recreational sports does not influence family resilience or communication facilitation. Rather, it was found that the length, frequency and quantity of a family participating in recreational sports are an important factor for family resilience and communication facilitation.

\section{CONFLICT OF INTEREST}

There are no potential conflicts of interest relevant to this article.

\section{REFERENCES}

Anderson JC, Gerbing DW. The effect of sampling error on convergence, improper solutions, and goodness-of-fit indicates for maximum likelihood confirmatory factor analysis. Psychometrika 1998;49:155-173.

Choi K. The influence of family leisure activities on emotional dynamics. Korean J Physic Edu 2003;42(3):175-184.

Hawley DR, Dehaan L. Toward a definition of family resilience: Integrat- ing life-span and family perspectives. Fam Process 1996;35:283-298.

Hyun, E. Adjustment of single parent family: The buffering effect of family resilience. Korean J Home Manag 2007;25(5):107-126.

Jeong $\mathrm{KH}$. The influence of the types of participation in leisure sports activities of family on communication facilitation, gap, conflict and conflict tactics behavior between old and new generations. Korean J Sociol Sport 2006;19:373-392.

Kim K. Relations among leisure attitude, perceived leisure competence, and family satisfaction of the family groups participating in skiing activities. Korean J Sociol Sport 1999;12:295-306.

Koo J, Lee G. The relationship of baby boomers' participation motivation in leisure sports with recovery resilience and life satisfaction. J Exer Rehabil 2013;9:263-270.

Lim, T. Young people's perception of intergenerational communication. Korean J Commun Stud 1999;43:244-269.

Vallerand RJ, Bissonnett R. Intrinsic, extrinsic, and motivational types as predictor of behavior: A prospective study. J Personal Soc Psychol 1992;60:599-620.

Walsh F. Family resilience framework: Innovative practice applications. Family Relations 2002;1:130-137.

Williams A, Giles. Young people's beliefs about intergenerational communication: An initial cross-cultural comparison. Commun Res 1996; 24:422-438

Yang IJ. Jeong exchange and collective leadership in Korean organizations. Asia Pacific J Manage 2006;23:283- 298.

Yi E, Kang E. The influence of leisure activities with family members of elementary school students on family resilience and communication between family members. J Sport Leisure Stud 2009;36:1073-1083. 